مجلة
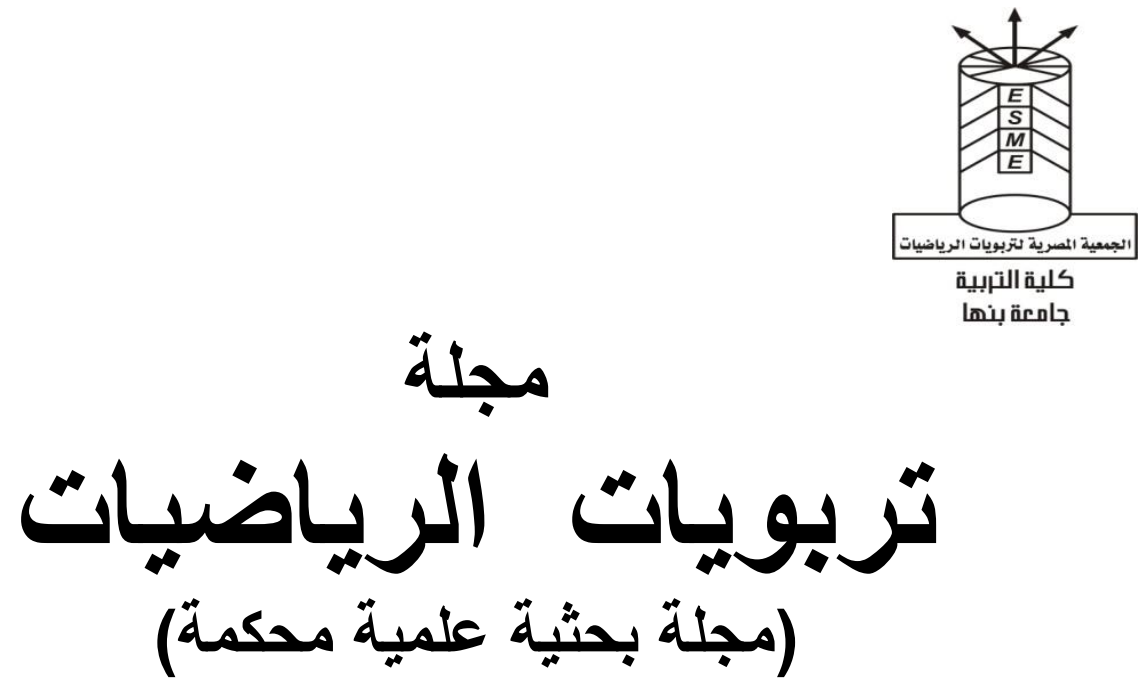

هيئة التحرير

\begin{tabular}{|c|c|c|}
\hline الكلية والجامعة & الاســــــم & الصفة \\
\hline التربية _عين شمس & أ.د.محمد أمين المفتي & رئيس التحريز \\
\hline الار اسـات العليا للتربية ـ القاهرة & أ.د. مصطفى عبد السميع & \multirow{9}{*}{ أعضاء } \\
\hline التربية - بنهـ & أ.د. العزب محمد زهـران & \\
\hline 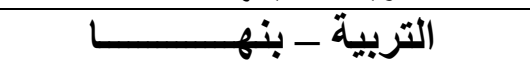 & أ.د. علاء الدين سعد متولى & \\
\hline الار اسـات العليا للتربية _ القاهرة & أ.د.وائل عبدالله محمد علي & \\
\hline التربية ــ الملك سعود & أ.د.هشام بركات حسين & \\
\hline التربية ـ الطفيلية ـ الأردن & أ.د.تيسير خليل القيسي & \\
\hline التربية ـ ميسان - العراق & أ.د. عمار طعمه الساعدي & \\
\hline التربية ـ الفيوم & د.أحمد إبر اهيم خطاب & \\
\hline التربية - بنهـــــا & د.إبراهيم التونسي السيد & \\
\hline
\end{tabular}

المجلد (Y (Y) العدد (צ) (צ')

أبريل • r · r م (الجزء الثاني) 
مجلة تريويات الرياضيات

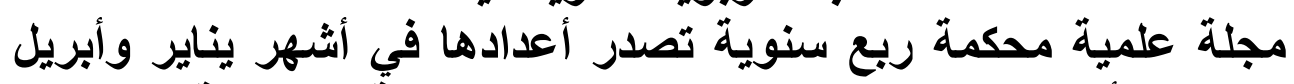

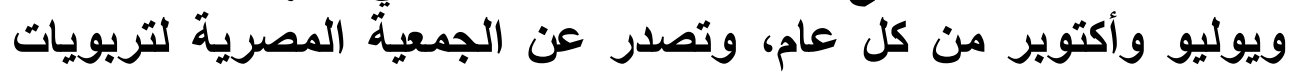

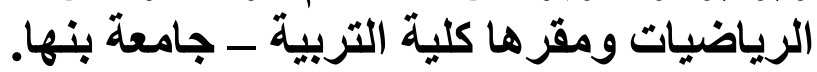

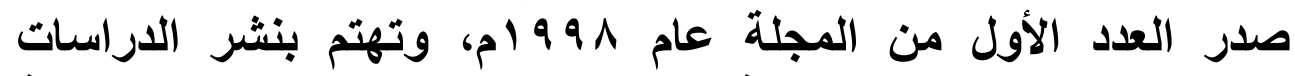

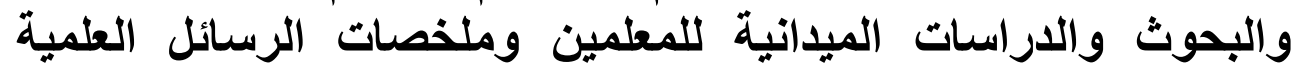

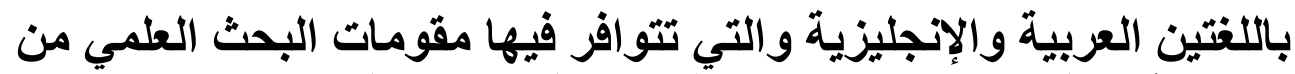

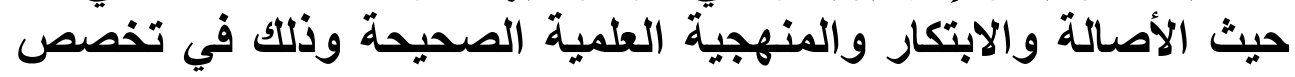

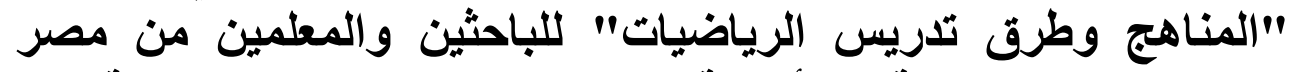

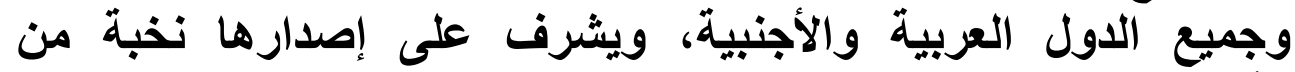

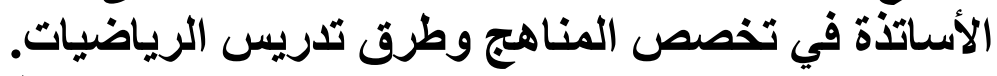

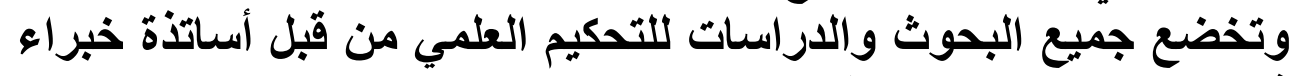

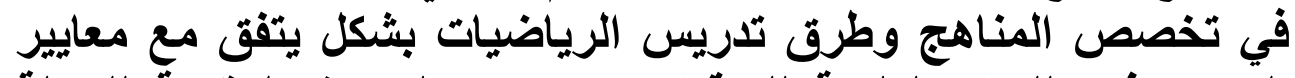

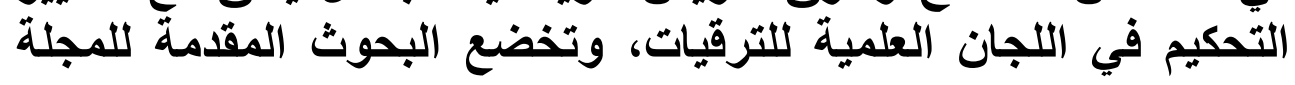

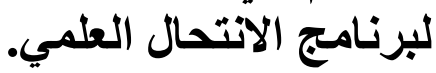

رقم الإيداع بار الكتب المصرية : $18117 / 2009$ الكائ

(Print) : (ISSN 2090-0562)

(Online) : (ISSN 2682- 4337)

الموقع على بنك المعرفة المصري

http://armin.journals.ekb.eg/

جميع حقوق الطبع والنشر محفوظة

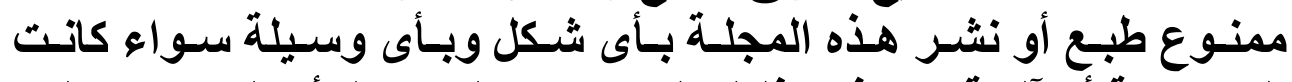

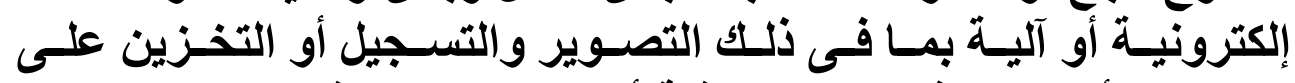

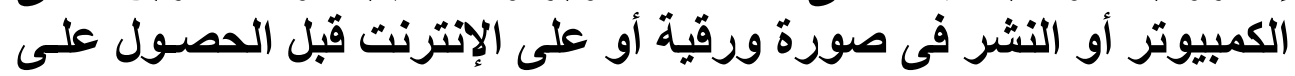

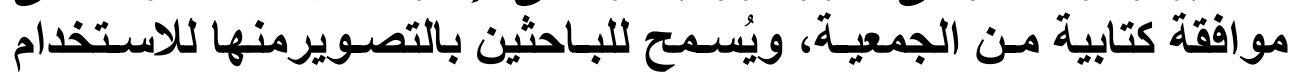
الثخصى لغرض البحث العلمى.

EM: mathedu1997@ hotmail.com

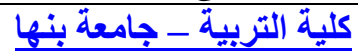




\section{قواعد النشر بالمجلة}

() تقبل المجلة نشر البحوث و المقالات التي لم يسبق تقديمها إلى جهات علمية

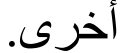

r) تقدم البحوث مطبو عة على الكمبيوتر ، بخط Times New Roman بنط

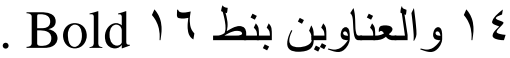

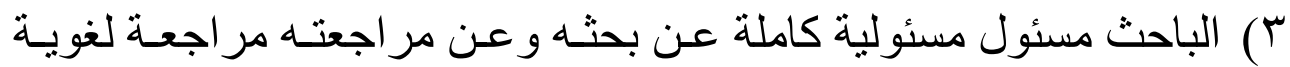

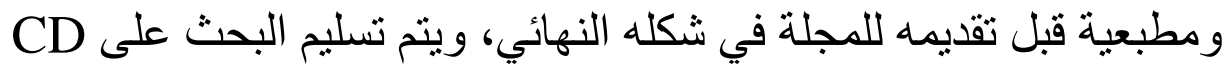
أو عبر الإيميل mathedu1997@hotmail.com ع) يقدم الباحث مستخلصاً باللغة العربية وآخر باللغـة الإنجليزيـة في حدود صفحة و احدة.

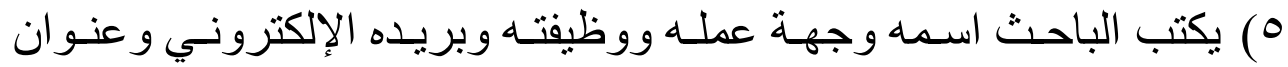
البحث على صفحة مستقلة ببداية البحث.

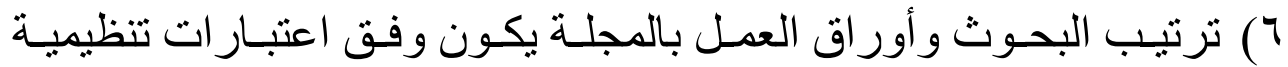
خاصة بالمجلة و لاعلاقة لها بمكانة البحث أو البه الباحث.

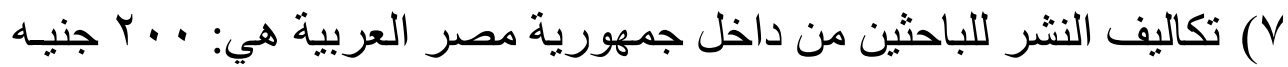

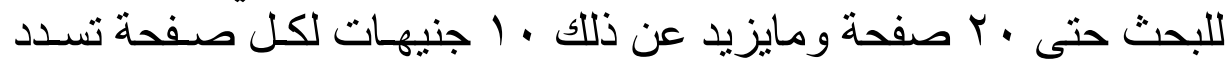

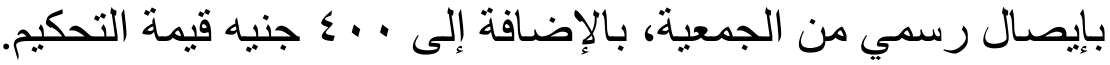

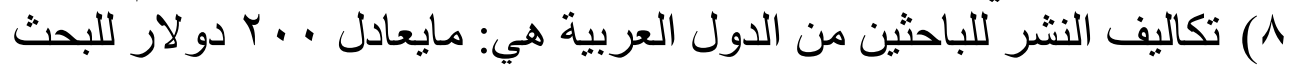

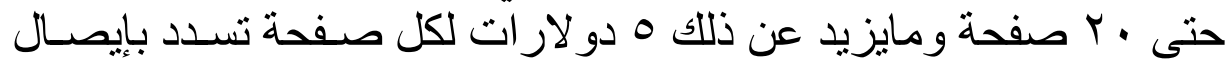

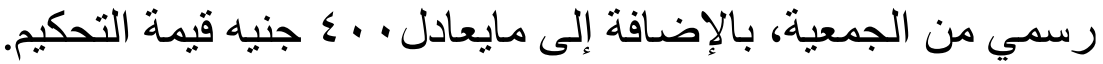

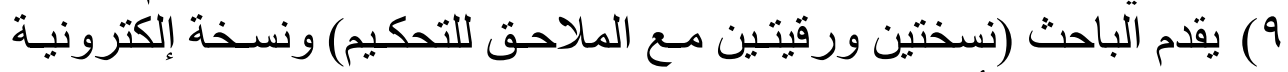

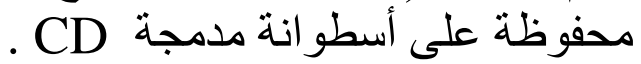

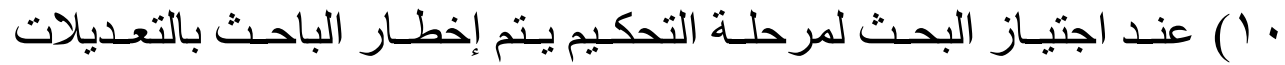

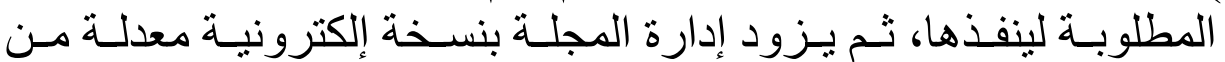

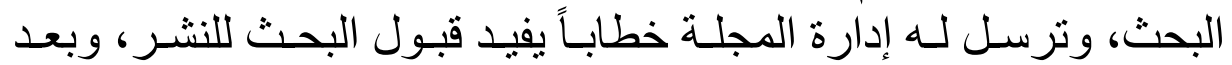

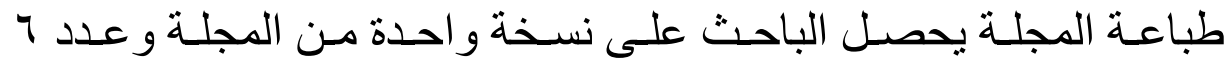
مستلات من بحثة. 11) جميع أعداد المجلة يتم نشر ها إلكترونياً على موقع الجمعية. 


\section{الهيئة الاستشارية لتحكيم بحوث المجلة \\ (مرتبون أبجدياً)}

\begin{tabular}{|c|c|c|c|c|}
\hline 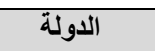 & الجامعة & البريد الاكتروني & الاسم كاملا بالعربية & \\
\hline ال الاردن & الجامعة الأردنية & i.shara@ju.edi.jo & أ.د/ ابراهيم احمد الثرع & .1 \\
\hline مصر & جامعة الزقازيق & drebrahimattia@yahoo.com & أ.د/ ابراهيم أحمد السيد عطية &.$r$ \\
\hline 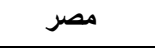 & جامعة بورسعيد & Imrefaat72@yahoo.com & أ.د/ ابراهيم رفعت إبراهيم &.$^{r}$ \\
\hline السعودية & جامعة شقراء & amabdullah@su.edu.sa & أ.د/ ابراهيم محمد عبدالله &.$\varepsilon$ \\
\hline مصر & جامعة طنطا & i.shara@ju.edi.jo & أ.د/ ابر اهيم حسن عساف & .0 \\
\hline مصر & جامعه المنيا & amoustaf@hotmail.com & أ.د/ أحمدالسيد مصطفي & .9 \\
\hline 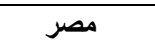 & جامعة طنطا & dr.ahmedr@edu.tanta.edu.eg & أ.د/ أحمد محمد الرفاعي &.$V$ \\
\hline 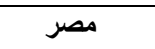 & جامعة بنها & alazabzahran@hotmail.com & أ.د/ العزب محمد زهران &.$\wedge$ \\
\hline مصر - إ مصر & المركز القومي للامتحانات والتقويم & abarashedd@yahoo.com & أ.د/ أشرف راشد علي & .9 \\
\hline السعودية & جامعة أم القرى & I_h_assaf@hotmail.com & أ.د/ بثينة محمد بلر & $.1 \cdot$ \\
\hline الأردن & جامعة الطفيلة التقتية & dralaadralaa@yahoo.com & أ.د/ تيسير خليل بخيت القيسي & .11 \\
\hline مصر & جامعة سوهاج & gamalhamid77@yahoo.com & أ.د/ جمال حامد محمد منصور & $.1 Y$ \\
\hline مصر - ال مصر & جامعة أسيوط & fkryabo@yaboo.com & أ.د/ جمال محمد فكري خليفة & $.1 \%$ \\
\hline 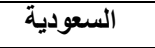 & جامعة الملك خالد & dr_hamza@hotmail.com & أ.د/ حمزة عبد الحكم الرياشي & $.1 \varepsilon$ \\
\hline السعودية & جامعة الامام محمد بن سعود & kalkhuzaim@gmail.com & أ.د/ خالد محمد ناصر الخزيم & .10 \\
\hline الأردن & جامعة آل البيت & khnejem@yahoo.com & أ.د/ خميس موسى خميس نجم & .17 \\
\hline سلطنة عمان & جامعة السلطان قابوس & abuelwan@squ.edu.om & أ.د/ رضا ابو علوان السيد & $.1 \mathrm{~V}$ \\
\hline مصر & جامعة بنها & abouserie@ hotmail.com & أ.د/ رضا عبدالله أبو سريع & .11 \\
\hline 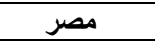 & جامعة دمياط & Rmasar@hotmail.com & أ.د/ رضا مسعد السعيد عصر & .19 \\
\hline مصر & أسيوط & Refaatelmeligy@yahoo.com & أ.د/ رفعت محمد المليجي &.$r \cdot$ \\
\hline 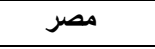 & جامعه المنيا & Z_2004eg@yahoo.com & أ.د/ زينب أحمد عبد الغتي &.$r^{\prime}$ \\
\hline 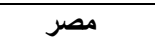 & جامعة اسيوط & zotiefy@yahoo.com & أ.د/ زينب محمود عطيفي &.$Y^{Y}$ \\
\hline 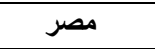 & جامعة المنوفية & sgmenoufy@yahoo.com & أ.د/ سعيد جابر المنوفي &.$r^{r}$ \\
\hline 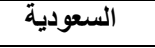 & جامعة الملك سعود & Salshalhoub@ksu.edu.sa & أ.د/ سمر عبدالعزيز الثلهوب &.$r \varepsilon$ \\
\hline 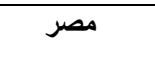 & جامعة قناة السويس & shabanhefny@hotmail.com & أ.د/ شعبان حفني شعبان &.$r^{\circ}$ \\
\hline مصر & جامعة قناة السويس & shabanhefny@hotmail.com & أ.د/ شعبان حفني شعبان & .84 \\
\hline مصر & جامعة عين شمس & Shreen.salah@yahoo.com & أ.د/ شيرين صلاح عبد الحكيم &.$r V$ \\
\hline الارددن & الجامعة الأردنية & h2000hrty@gmail. Com & أ.د/ صبري محمد حتوت &. $\mathrm{r}$ \\
\hline 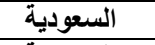 & جامعة طيبة ، السعودية & tsalharbi@hotmail.com & أ.د/ طلال الحربي &.$r^{9}$ \\
\hline 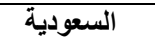 & جامعة الملك خالد & alshehri2014997@gmail.com & أ.د/ ظافر فراج هزاع الثهري &.$r \cdot$ \\
\hline ( ) مصر & جامعة الزقازيق & adelalbaz@yahoo.com & أ.د/ عادل إبراهيم الباز & .1 \\
\hline السعودية & جامعة تبوك & Aa.albalawi@ut.edu.sa & أ.د/ عايد بن علي البلوي &.$r Y$ \\
\hline مصر & جامعة الزقازيق & Hah_mrmr2003@ hotmail.com & أ.د/ عايدة سيدهم إسكندر &.$r r$ \\
\hline مصر & جامعة دمياط & Prof41260@yahoo.com & أ.د/ عبد الناصر أنيس عبدالوهاب &.$r \varepsilon$ \\
\hline
\end{tabular}




\begin{tabular}{|c|c|c|c|c|}
\hline 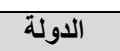 & الجامعة & البريد الاككتروني & الاسم كاملا بالعربية & \\
\hline السعودية & جامعة حائل & a.altamimi5@gmail.com & أ.د/ عبدالرحمن ابراهيم التميمي &.$r_{0}$ \\
\hline 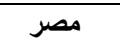 & جامعة بنها & lana_dana2005@yahoo.com & أ.د/ عبدالقادر محمد عبدالقادر & .47 \\
\hline مصر & جامعة عين شمس & Drazza2006@yahoo.com & أ.د/ عزة محمد عيد السميع &.$r v$ \\
\hline 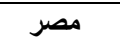 & جامعة بنها & Dr_hasaballa@gmail.com & أ.د/ علاء الدين سعد متولي &.$r \Lambda$ \\
\hline مصر & جامعة الزقازيق & aabdelrahim@gmail.com & أ.د/ على عبد الرحيم حسانين &.$r q$ \\
\hline العراق & جامعة ميسان & m_alnatheer@yahoo.com & أ.دد/ عمار طعمة جاسم الساعدي & . \\
\hline مصر & جامعة أسيوط & tdary6000@yahoo.com & أ.د/ عوض حسين التودري & . \\
\hline السعودية & جامعة ام القرى & Uqusmt@gmail.com & أ.د/ عوض صالح المالكي & 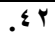 \\
\hline 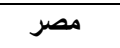 & جامعة بورسعيد & tamtam_hadid@yahoo.com & أ.د/ فاطمة عبد السلام ابو الحديد & . \\
\hline مصر - مصر & جامعة عين شمس & fmmina@link.net & أ.د/ فايز مراد مينا &.$\leqslant \xi$ \\
\hline 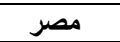 & جامعة أسيوط & Fayzahamada33@gmail.com & أ.د/ فايزة احمد محمد حمادة & .0 \\
\hline 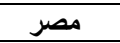 & جامعة المنوفية & fatiha_batikh@yahoo.com & أ.دد/ فتيحة أحمد بطيخ &.$\leqslant 7$ \\
\hline مصر & جامعة دمياط & Maths_proff@yahoo.com & أ.د/ فريال عبده عبده أبو ستة &.$\leqslant V$ \\
\hline الأردن & جامعة عمان العربية & zfhalshehri@hotmail.com & أ.د// فريد كامل أبوزينة &.$\leqslant \Lambda$ \\
\hline 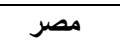 & جامعة المنصورة & fouadmm50@yahoo.com & أ.د/ فؤاد محمد موسى &.$\$ 9$ \\
\hline مصر & جامعة الاسكندرية & magda33saleh@yahoo.com & أ.د/ ماجدة محمود صالح & .0 \\
\hline 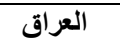 & جامعة بغذاد & dr.mejbel.aljouani@gmail.com & أ.ذد/ مجبل حماد عواد الجوعاني & .01 \\
\hline 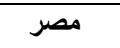 & جامعة عين شمس & elmofti44@hotmail.com & أ.د/ محمد أمين المفتى & $.0 Y$ \\
\hline السعودية & جامعة الملتك سعود & alnatheer@ksu.edu.sa & أ.د/ محمد بن عبدالله النذير & .04 \\
\hline 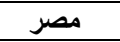 & جامعة المنيا & prof.r_58@yahoo.com & أ.د/ محمد ربيع حسني & $.0 \leqslant$ \\
\hline مصر & جامعة دمياط & dr.hasaballa@gmail.com & أ.د/ محمد عبد الحليم حسب الله & .00 \\
\hline 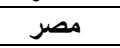 & جامعة بنها & mibadr@gmail.com & أ.د/ محمود إبراهيم بلر & .07 \\
\hline 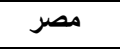 & جامعة بني سويف & m_nasr1010@yahoo.com & أ.دد/ محمود أحمد نصر & $.0 \mathrm{~V}$ \\
\hline 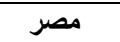 & جامعة أسيوط & mhawad2000@yahoo.com & أ.د/ محمود حسن عوض & .01 \\
\hline 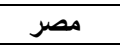 & جامعة الزقازيق & morad1955@hotmail.com & أ.د/ محمود عبد/اللطيف مراد & .09 \\
\hline 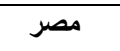 & جامعة أسيوط & mhawad2000@yahoo.com & أ.د/ محمود محمد حسن عوض &. \\
\hline مصر & جامعة بنى سويف & madihahm2004@yahoo.com & أ.د/ مديحة حسن محمد & .71 \\
\hline 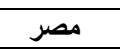 & جامعة عين شمس & drmervat23@yahoo.com & أ.د/ مرفت محمد كمال & $.7 r$ \\
\hline السعودية & جامعة الملك سعود & D_qaysee@ hotmail.com & أ.د/ مسفر بن سعود السلولي & r \\
\hline 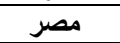 & عين شمس & Makka.elbanna@women.asu.edu.eg & أ.د/ مكة عبد المنعم البنا & $.7 \varepsilon$ \\
\hline 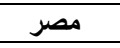 & جامعة طنطا & nagimichael@ hotmail.com & أ.د/ ناجي ديسقورس ميخائيل & .70 \\
\hline 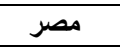 & جامعه طنطا & Nabilahimaya@hotmail.com & أ.د/ نبيله زكى ابراهبم & .74 \\
\hline مصر & جنوب الوادي & nasrmowd@gmail.com & أ.ذد/ نصر الله محمد محمود معوض &.$T V$ \\
\hline مصر & جامعة عين شمس & info@nazla-khedre.com & أ.د/ نظلة حسن خضر & .71 \\
\hline السعودية & جامعة الأميرة نورة بنت عبد الرحمن & Dr.nawal123@hotmail.com & أ.د/ نوال محمد الراجح العنقري & .79 \\
\hline السعودية & جامعة الملك سعود & misfer5@yahoo.com & أ.د/ هشام بركات بشر حسين &.$v$. \\
\hline 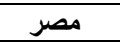 & جامعة القاهره & drwaelabdallah@gmail.com & أ.د/ وائل عبد الله محمد على & .61 \\
\hline مصر & جامعة القاهره & wmkefafe@cu.edu.eg & أ.د/ وفاء مصطفى محمد كفافي &.$V Y$ \\
\hline مصر & جامعه المنيا & dryasmenzedan@yahoo.com & أ.د/ ياسمين زيدان حسن &.$v r$ \\
\hline مصر & جامعة طنطا & dr.yelemam@gmail.com & أ.د/ يوسف الحسيني الامام & $. V \leqslant$ \\
\hline
\end{tabular}




\section{محتويات العدد}

1) واقع امتلاك المتخصصون في الرياضيات بجامعة حفر الباطن للمعرفة التربوية $\checkmark$ التكنولوجية وفق إطار (TPACK).

لد. سلمان بن حديد الشمري .....................

r أثر استخدام نموذج ألن هوفر في تنمية مهارات حلّ المشكلات الهندسيَّة لاى طالبات rı الصف الثاني متوسط.

r r تحليل محتوى كتب الرياضيات بالمرحلة المتوسطة في ضوء مهارات التفكير الإحصائي.

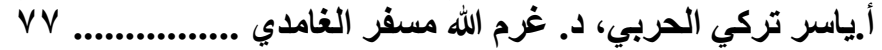

؛) الضعف في حل المسائل الرياضية اللفظية لدى طلاب المرحلة الابتدائية: أسبابه $1 \cdot 1$ د.علي بن منصور حزام الجعفري

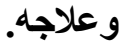

ه) أثر الامج بين بيئات CAS و DGS التفاعلية في التفكير الهندسي لاى طلبة التعليم

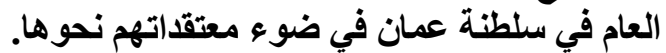

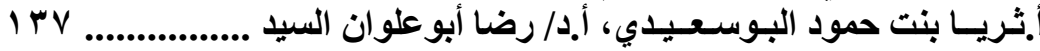

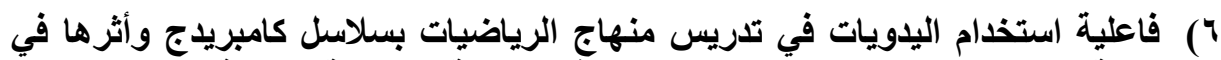

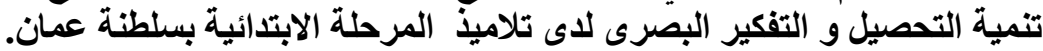

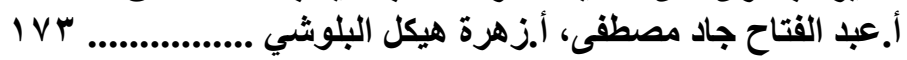

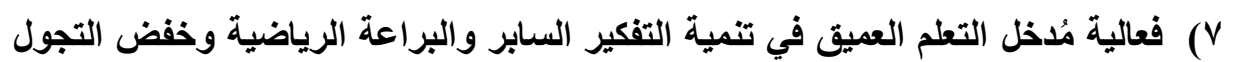
العقلي لدي طلاب المرحلة الثانوية.

PIV دلف الله حلمي فاوى محمد ...................

^) تقويم الأداء التدريسي لمعلمات الرياضيات بالمرحلة المتوسطة في المملكة العربية

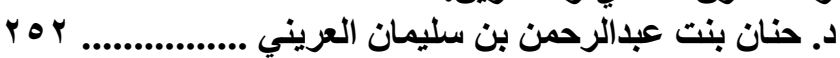

